\title{
Bullying at Workplace Affecting Motivation and Organizational Citizenship Behavior of Branch Banking Staff in Major Cities of Pakistan
}

\author{
Syed Fahad Ali, Mubeen Butt \\ Damen Support Programme, European University of Business, Berlin, Germany \\ mubeen.butt89@gmail.com
}

\begin{abstract}
The banking sector has been considered as one of the top career priority choices of University Graduates in Pakistan over the past decades. But since the banks got privatized branch banking has mainly been observed as one of the most hatred areas of deployment for any employee. The objective of this investigation was to analyze that bullying affects motivation and employees consider it as part of the routine and stays motivated and committed to their organization, which is possible due to several reasons in which one could be fewer job opportunities and financial issues. Results of this investigation will help the Banks management for decision making in order to improve their working culture and will also trigger future researchers to further investigate these findings. We took Branch banking Staff from all banks across Pakistan as population and were able to manage a sample size of 271 (validated as 248) from different cities and brands of banks under the snowball sampling technique by using a cross-sectional research design. Data was collected through structured questionnaires via google forms with help of social media forums. Data Analysis was conducted through SPSS and in the initial analysis. We did not find any symptoms of multicollinearity in our data; therefore, a linear relationship between motivation (IV) and organizational citizenship behavior, henceforth abbreviated as OCB, (DV) was found. Further Pearson correlation reflected a significant and positive relationship between motivation and OCB. $71 \%$ variation was explained through the regression model of motivation and OCB with a positive relationship whereas moderation of bullying was proved with $35 \%$ variation explained.
\end{abstract}

Keywords: Bullying: Workplace; Organizational Citizenship; Branch Banking Employees

\section{INTRODUCTION}

The banking industry has contributed tremendously to the economy of Pakistan over the years [1]. Along with financial facilitation for the businesses and individual consumers it has also created employments [2].

The world's economy is mainly dependent on the banking system and an effective banking system is known as the backbone of any economy. Specifically, developing countries like Pakistan keeps a major focus on the banking sector in order to sustain in the global market due to the globalization of banking operations [3].

We can expect banks to use different tools in order to increase their overall performance by keeping a close eye on their human capital. While taking care of human capital Banks may have to improve their organizational cultures, employee retention, motivation, and commitment [4]. High staff turnover has been observed in the Pakistani banking Industry due to different reasons which also include abusive supervisor behavior [5].

We wanted to explore that how bullying as an independent variable affects the relationship of motivation and OCB of branch banking staff in Pakistan. We reviewed different papers highlighting the relationship between motivation and OCB but we wanted to analyze the effects of bullying on motivation and OCB. Further, we did not find evident work of bullying in Pakistani in branch banking culture of Pakistan which encouraged us for this research.

Bullying and job stress in the banking sector of Pakistan are analyzed as in direct relationship whereas job performance has been analyzed as in indirect relation with bullying [6]. Bullying leads to turnover intentions [7].

A weak relation was analyzed between motivation, commitment, and job involvement in the banking sector of Pakistan [8]. There is a significant relationship between professional growth, professional preparation, along with job fulfillment, and professional dedication [9]. The above-explained scenarios create room to examine either Bullying will influence the motivation and cob of employees despite having a long-lasting career path in banking as we did not witness any such investigation which reflects how bullying will distract an employee from having a longlasting career in banking.

This research will address the following questions.

1. What is the effect of Motivation on OCB in Branch banking Staff in major cities of Pakistan? 
2. How bullying affects, the Relationship of Motivation and OCB in Branch banking Staff in major cities of Pakistan.?

The objectives of this research are:

1. To identify the relationship between motivation and organizational citizenship behavior of branch banking staff in major cities of Pakistan.

2. To describe the influence of bullying on motivation and OCB of branch banking staff in major cities of Pakistan.

Many studies have recommended developing of anti-bullying culture at the organizational level in order to improve the working environment [10]. At the workplace, employees make friendships through sharing common interests and outcomes of mutual benefits and expect the same from their colleagues as well [11]. In countries where different cultures exist mostly friendships are created through positive interaction [12]. This study will help the banking sector in improving their working culture by eliminating the factors affecting the motivation and organization citizenship of their branch banking staff. In turn, it will further create positivity, healthy working culture, and retention of staff. This study will also reflect that either being bullied influence the mindset of staff or they consider it as part of the game and carry on with their jobs. In addition to work stress, bullying could be an additional psychological stress factor for the bankers which may lead to low-performance level or involuntary job exit.

\section{LITERATURE REVIEW}

Workplace bullying (WB) has been defined as unfriendly and bad communication, targeting an individual by one or more individuals [13]. Either bullying is a new concept or born from the surroundings or whether it has been there by default but never identified before [14].

Organizational citizenship behavior is studied that job satisfaction, perceived fairness, leader supportiveness, and organizational commitment are all antecedents of organizational citizenship behaviors [15]. The last type of behavior explained by Katz [16] has been elaborated by Smith, Organ, and Near [17], who explained the importance of citizenship behaviors as a lubricant for the social machinery of any organization by providing work flexibility in any possible situation. As citizenship behaviors are roles played by an individual beyond his formal job description, they cannot be enforced by force. Such behaviors can be beneficial more for fellow employees than one's self [17]. Thus, it can be concluded that organizational citizenship behaviors are those optional extra-role behaviors that are beneficial for the organization [15]

Motivation has been described as "a motive is a reason for doing something. Motivation is concerned with the factors that influence people to behave in certain ways" [18]. An Intrinsically motivated person is motivated only for the reason that performing some specific task provides him internal satisfaction. But when some external reward is attached with the performance of that task, the locus of causality shifts from his behavior to the environment, and the level of his intrinsic motivation reduces [19], [20].

Motivation can be one of the factors to attain organizational citizenship behavior [21]. The expectancy theory of motivation can be used to forecast organizational citizenship behaviors [22]. Organizational citizenship behavior is much affected by intrinsic motivation [23]. Employees with intrinsic motivation will participate in activities, they enjoy and as result, the work environment will be pleasant and free from stress for themselves as well as for everyone working around them. It can be assumed that such workers will be inclined to help their fellows and create a helping environment, resulting in doing extra-role activities i.e. will show organizational citizenship behaviour [24]. Although both intrinsic and extrinsic motivation can put an impact on employee behavior [25].

Workplace bullying has been happening globally in organizations over the years [26]. As workplace bullying negatively affects employees' health, wellbeing, and productivity at the workplace [27]. Based on this literature, hypotheses for this study are established as follows:

$\mathrm{H}_{1}$ : An increase in motivation leads to an increase in OCB.

$\mathrm{H}_{2}$ : Bullying moderates the relationship between motivation and OCB. 

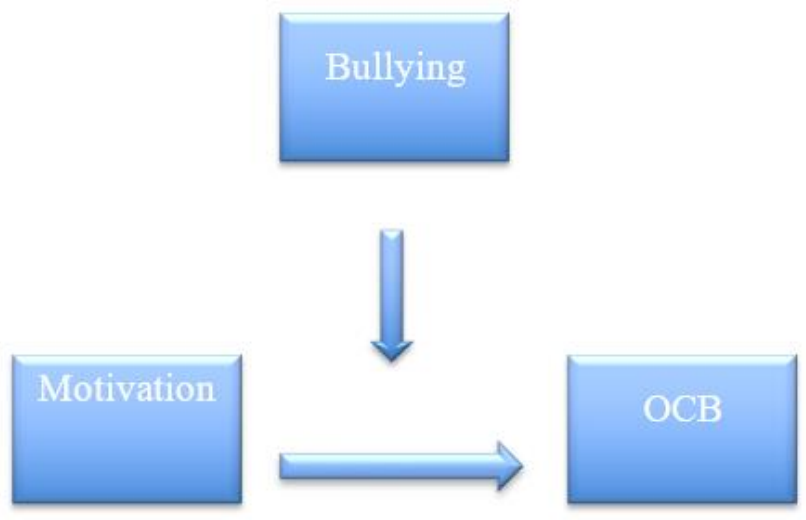

Figure 1 Theoretical Framework

\section{RESEARCH METHODS}

A cross-sectional research design was being used for this study. As defined by Sekaran and Bougie [28], "A research study for which data are gathered just once (stretched though it may be over days, weeks, or months) to answer the research question" ( $p-390)$.

Due to the pandemic situation of COVID-19 and restrictions, open visits were not possible in banks; therefore, personal contacts with bankers in industry and social media were used.

We tried to get maximum responses in order to have reasonable data for analysis. The sample size for this study was determined in accordance with the rule of thumb described by [29], i.e. minimum of five responses for each item included in the questionnaire. We were able to manage a sample size of 271 which was further validated as 248 .

We used a non-probability sampling technique, i.e. snowball sampling method to collect the sample data. We spread the google forms link among the targeted population through social media (WhatsApp, Facebook, LinkedIn), and as a chain referral, it was further spread in order to receive maximum responses from the major cities of Pakistan.

The data was collected through Google forms with a structured questionnaire, sent to the branch banking staff in different cities through social media (WhatsApp, Facebook, LinkedIn). Data were collected from a sample of 271 professional and personal contacts in the banking sector.

The SPSS (Statistical Product and Service Solutions) Software and PROCESS software, developed by Hayes, [30], were used for data analysis.
The questionnaire for the survey included questions related to demographic information (e.g. age, qualification, designation, city, bank's name) and selfcompletion measures for employee motivation, bullying, and organizational citizenship behavior.

The motivation sources inventory (MSI) scale by Barbuto $\mathrm{Jr}$ and Scholl [31] was used to measure motivation. The instrument consisted of five six-item subscales, measured on five-point Likert scales, ranging from (1) "strongly disagree" to (5) "strongly agree."

P. M. Podsakoff et al. [32] developed an instrument consisting of 24 to measure organizational citizenship behavior. It was later adapted by Kumar and Shah [33] by whom the instrument was reduced to 15 items, measured on seven-point Likert Scales ranging from (1) "strongly agree" to (7) "strongly disagree". We used the adapted version in this study.

Three measures of bullying were used: two single questions and one index. The first question on actual exposure to bullying was "Have you been subjected to bullying at the workplace during the last six months?" The following options were the alternatives: "no," "seldom," "now and then," "about once a week," and "many times a week". The second question was "Have you seen others being subjected to bullying at your workplace during the last six months?" This question had the options of "yes" and "no." The third measure we used was called the Bergen Bullying Index which is a global measurement of potential individual and organizational consequences of bullying and harassment. The Bergen Bullying Index consists of a four-point Likert scale from "agree strongly" to "disagree strongly."

\section{RESULTS AND DISCUSSION}

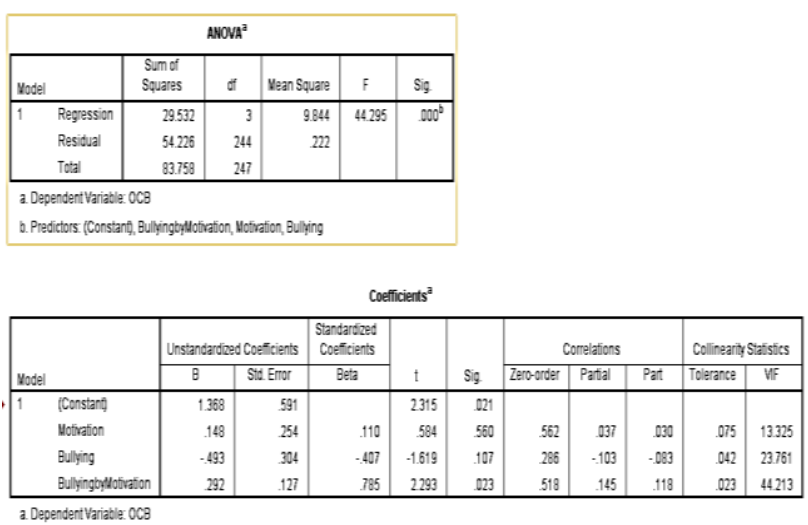




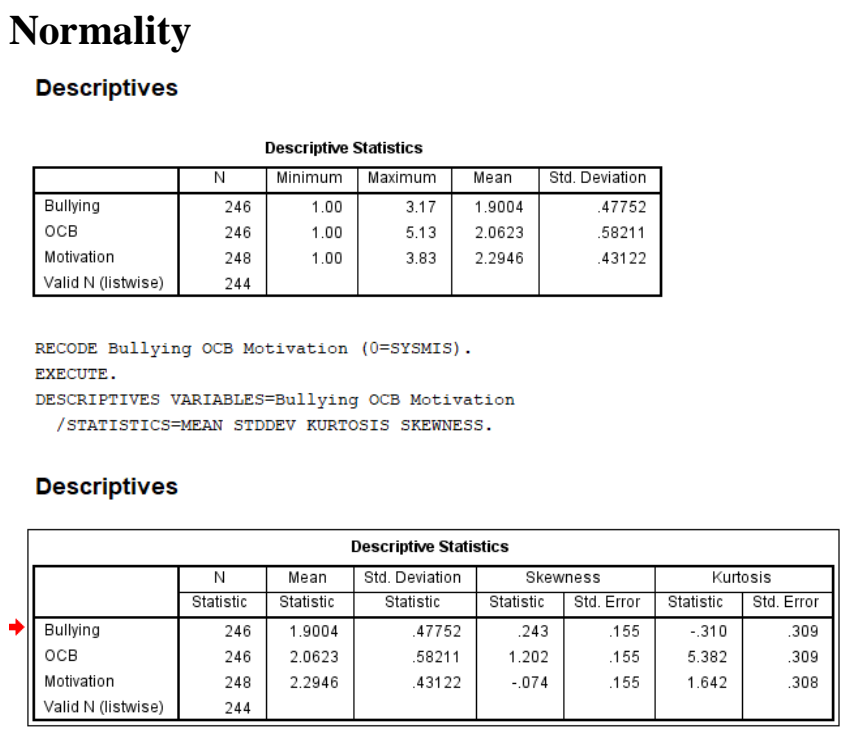

\section{Linearity}
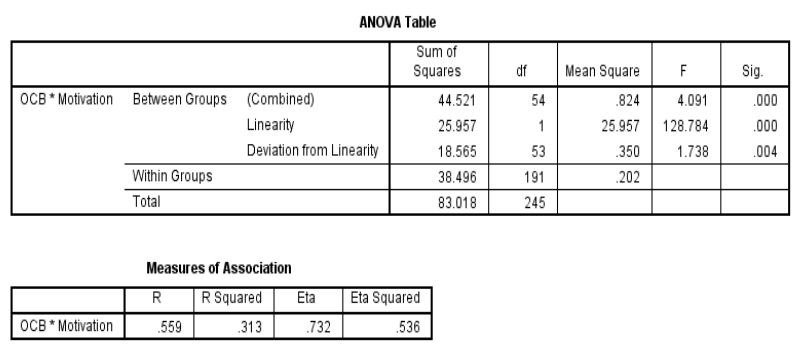

Linearity tests aim to determine the relationship between the independent variable and dependent variable is linear or not. based on the above Annova output table, value sig. and deviation from linearity is $0.004<0.05$. therefore, it can be concluded from the above table that there is a linear relationship between the variables of motivation with OCB.

\section{Crosstabs}

\section{Crosstabs}

\begin{tabular}{|c|c|c|c|c|c|c|}
\hline \multicolumn{7}{|c|}{ Case Processing Summary } \\
\hline & \multicolumn{6}{|c|}{ Cases } \\
\hline & \multicolumn{2}{|c|}{ Valid } & \multicolumn{2}{|c|}{ Missing } & \multicolumn{2}{|c|}{ Total } \\
\hline & $\mathrm{N}$ & Percent & $\mathrm{N}$ & Percent & $\mathrm{N}$ & Percent \\
\hline$O C B *$ Motivation & 248 & $100.0 \%$ & 0 & $0.0 \%$ & 248 & $100.0 \%$ \\
\hline
\end{tabular}
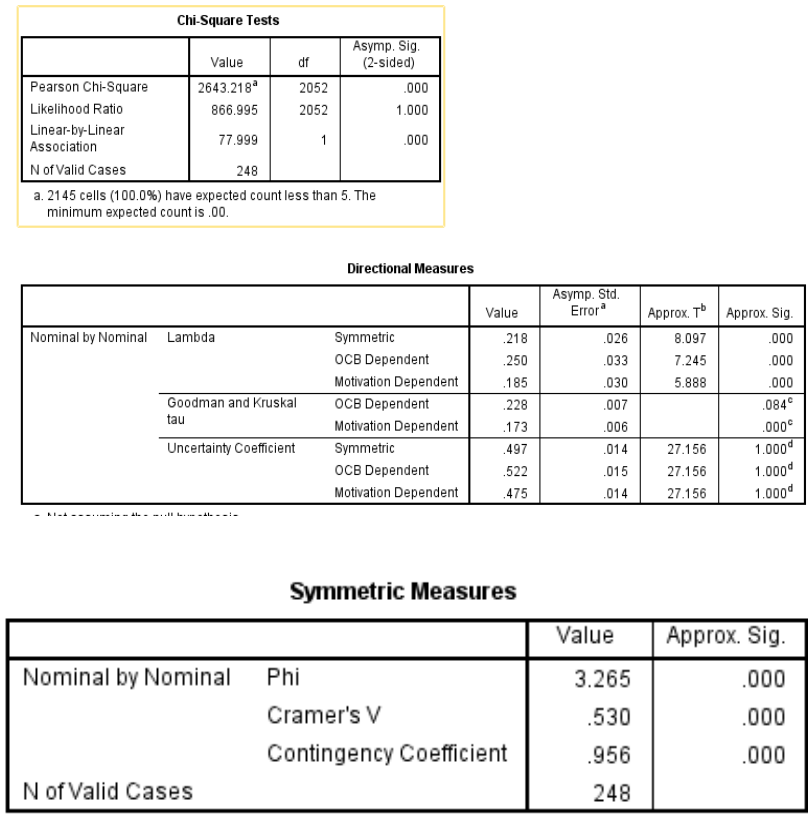

To check the association between OCB and Motivation in h.s. the chi-square test is conducted. The case processing summary table indicates that there is no participant with a missing value. The assumptions are checked through crosstabs.

The Chi-Square Tests table is used to determine if there is a statistically significant relationship between two dichotomous or nominal variables. It tells you whether the relationship is statistically significant but does not indicate the strength of the relationship, like phi or a correlation does. In the output, we use the Pearson Chi-Square or (for small samples) the Fisher's exact test to interpret the results of the test. They are statistically significant $(\mathrm{p}<.001)$, which indicates that there is a significant relationship between IV and DV. In this way, we are getting support for our hypothesis.

\section{Correlations}

\section{- Correlations}

\begin{tabular}{|c|c|c|c|}
\hline \multicolumn{4}{|c|}{ Correlations } \\
\hline & & $\mathrm{OCB}$ & Motivation \\
\hline \multirow[t]{3}{*}{$\overline{\mathrm{OCB}}$} & Pearson Correlation & 1 & $.562^{\mathrm{nn}}$ \\
\hline & Sig. (2-tailed) & & .000 \\
\hline & $\mathrm{N}$ & 248 & 248 \\
\hline \multirow[t]{3}{*}{ Motivation } & Pearson Correlation & $.562^{\mathrm{n}}$ & 1 \\
\hline & Sig. (2-tailed) & .000 & \\
\hline & $\mathrm{N}$ & 248 & 248 \\
\hline
\end{tabular}


To investigate if there was a statistically significant association between OCB and Motivation, a correlation was computed. Both the variables were approximately normal there is a linear relationship between them hence fulfilling the assumptions for Pearson's correlation. Thus, Pearson's $r$ is calculated, $\mathrm{r}=0.52, \mathrm{p}<.001$ relating that there is a highly significant relationship between the variables. The positive sign of the Pearson's test value shows that there is a positive relationship, which means that employees who have high motivation levels in their banks will result in high OCB vice versa.

\section{Regression Analysis}

Simple regression is used to check the contribution of the independent variable(s) in the dependent variable if the independent variable is one.

\begin{tabular}{|l|l|l|l|}
\hline Variables Entered/Removed & \\
\hline Model & $\begin{array}{c}\text { Variables } \\
\text { Entered }\end{array}$ & $\begin{array}{c}\text { Variables } \\
\text { Removed }\end{array}$ & Method \\
\hline 1 & Motivation $^{\mathrm{b}}$ & & Enter \\
\hline
\end{tabular}
a. Dependent Variable: OCB
b. All requested variables entered.

\begin{tabular}{|l|l|r|r|r|}
\multicolumn{7}{c|}{ Model Summary } \\
\hline Model & R & R Square & $\begin{array}{c}\text { Adjusted R } \\
\text { Square }\end{array}$ & $\begin{array}{c}\text { Std. Error of } \\
\text { the Estimate }\end{array}$ \\
\hline 1 & $.562^{\mathrm{a}}$ & .316 & .313 & .48266 \\
\hline
\end{tabular}

a. Predictors: (Constant), Motivation

Regression Analysis was conducted to investigate how well motivation predicts high OCB. The $\mathrm{R} 2$ value was .316 . This indicates that $31 \%$ of the variance explained through this regression model of motivation for OCB.
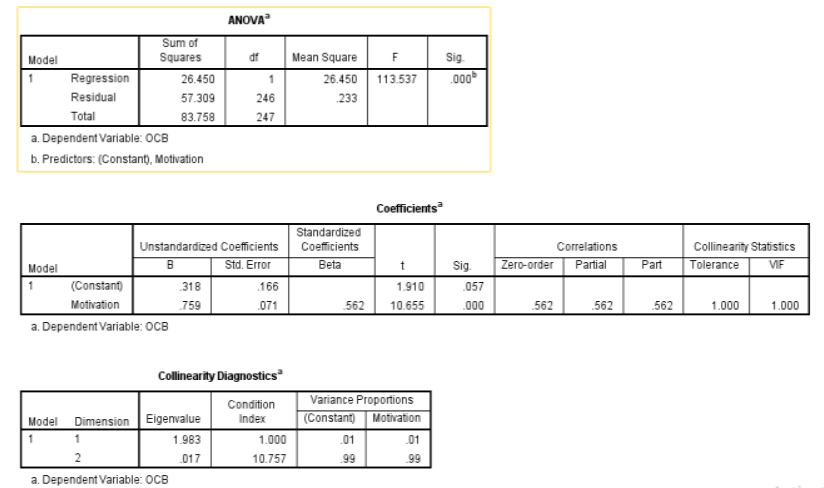

This regression model is significant as the ANNOVA value is 0.000 which explains that our P- value $<0.05$ and affirming the significant nature of variables.

As we are doing simple regression, so our regression equation is: $\mathrm{OCB}=0.3198+0.75$ (motivation).

According to the regression equation, the above estimates of the equation explain the relationship between the independent variable that is motivation, and the dependent variable that is OCB. Therefore, the above-mentioned estimates explain that the amount of increase in OCB would be predicted by a 1 unit increase in the predictor which is motivation. Basically, the beta value indicates that one-unit change in motivation will bring a 0.759 -unit change in OCB.

However, our regression analysis supports the significant relationship but the only element that has an issue is the eigenvalue which is 0.017 and it is close to zero. However, the literature explained that it should be far from zero. Therefore, for this, we will perform multicollinearity analysis.

\section{Multicollinearity}

To look for multicollinearity condition we can see multiple indications like in the coefficient table the tolerance value should be 1 which is present in our table. As for VIF, it should be less than, and in our analysis, it is $1<2$. This indicates that our analysis does not have a multicollinearity issue.

Now we come to collinearity diagnostics. If we see the condition index, the values of the abovementioned table are less than $15(1.00<15,10.757<15)$ therefore, this indicates that our analysis does not have a multicollinearity issue. However, the eigenvalue should be far from 0 . In our case, the eigenvalues are 1.983 which is far from 0 and the other is 0.17 which is close to 0 . So, the eigenvalue should be far from 0 . For this, we will run factor analysis on the variables to make the eigenvalue far from zero.
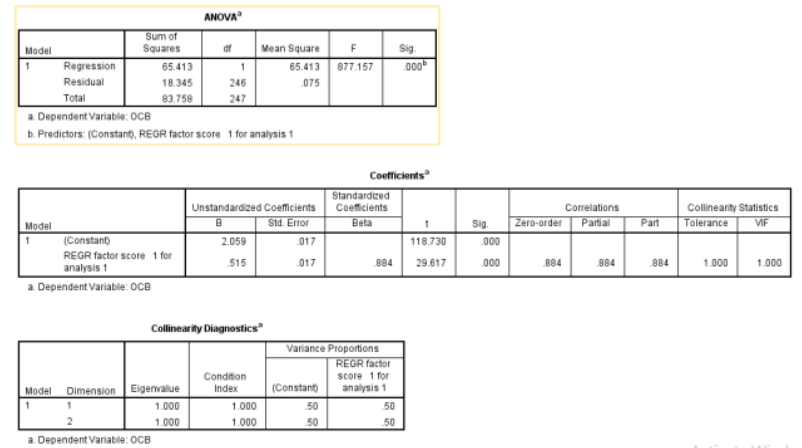
The ANNOVA table has 0.000 significant value. In the coefficient table, all the VIF values are less than 2 . The tolerance value of the variable is also 1 . As for the collinearity diagnostics, all the eigenvalues are far from zero so the condition index that is 1 . This advanced factor analysis technique has helped reduce the multicollinearity issue. After factor analysis, we will again perform regression analysis to see the chart and see if that supports our hypothesis.

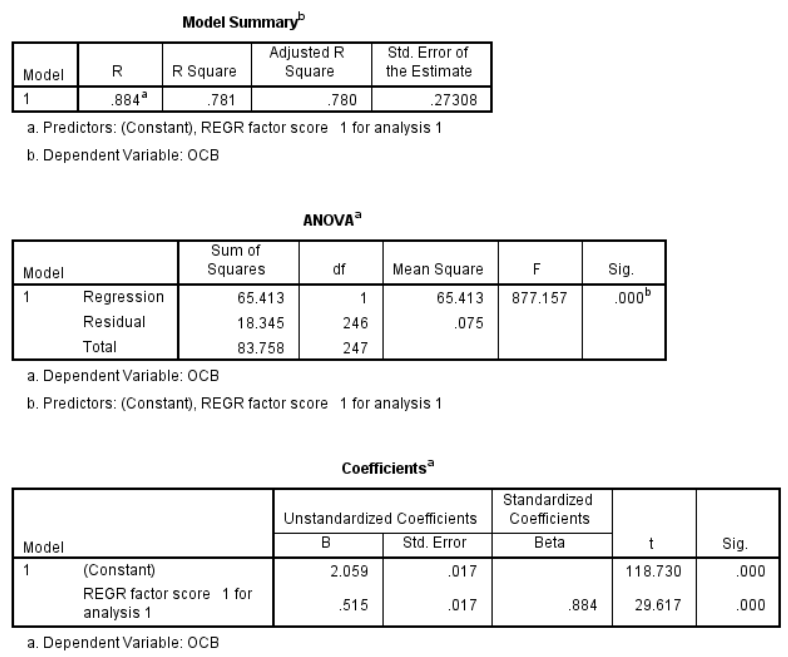

Here, The R2 value is .718 . This indicates that $71 \%$ of the variance explains through this regression model of motivation for OCB. The Annova table has 0.000 significant value which also explains the significant relationship between IV and DV. Therefore, it supports our hypothesis that an increase in motivation leads to an increase in OCB.

\section{Moderation}

After creating interaction terms between bullying (moderator) and motivation (IV), we performed regression analysis. Through the regression analysis, as below mentioned table depicts the ANNOVA table in which 0.00 explains the significant level of the framework. Here, The R2 value is .353. This indicates that $35 \%$ of the variance explained through this regression model of motivation for OCB. The interaction term is computed to check the combined effect of IV (motivation) and moderator (bullying) on DV (OCB).

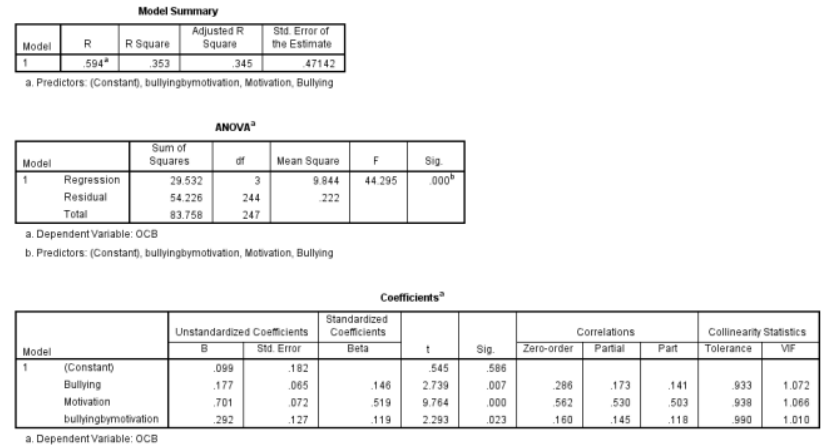

In the coefficient table, the significant moderator value is 0.023 which is less than 0.05 explaining the significant relation of moderator in the model. VIF value is less than 2 and the tolerance value is also close to 1 . From the above analysis, we conclude for moderator equation which is: $\mathrm{Y}=0.099+$ 0.177 *bullying $+0.701 *$ motivation $+0.292 *$ bullying by motivation.

The above regression analysis for moderation explains the significant use of bullying as a moderator between motivation, which is the IV, and OCB which is the DV. It shows that the presence of the moderator is negatively affecting the positive relationship between motivation and OCB. The increase in bullying of employees in banks will result in a decrease in motivation and OCB. The significant moderation supports the hypothesis. From the above-mentioned moderation analysis through SPSS, it has been concluded that there is a significant relationship between the moderator and IV and DV, which supports our hypothesis: bullying moderates the relationship between motivation and OCB.

\section{CONCLUSION}

With this study, we have seen a significant positive relationship between motivation on OCB in the branch banking staff which means that motivated employees will have a high level of organizational citizenship. We found that bullying affects positively the relationship between motivation and OCB which means any motivated and committed employee will feel demotivated and lose the commitment to the organization. This would indicate the bank's management to do some homework and make certain decisions to control Bullying to improve their working culture. It could be investigated further that what other factors and variables are affected by the bullying which could be beneficial for the bank in more than one way. 
Therefore, with this study, we have concluded that bullying has a negative effect which later on decreases the motivation and OCB in branch banking staff in Pakistan.

Due to covid19 restrictions, we were not able to visit or approach bankers openly. Further Branch banking sector has a spread across whole Pakistan with different brands of Pakistan. Though we tried to spread the questionnaire link among all brands and groups but yet it was not possible to pursue everyone for form filling. Also, once the questionnaire link was spread, we could only assess in the end that from which brand and city we have received a reasonable number of responses. However, we kept it open for all brands and cities to get representation from all over Pakistan.

\section{REFERENCES}

[1] Mughal, M. N. (2015). Impact of job characteristics on turnover intentions: A study of the front line employees in commercial banks. Academy of Contemporary Research Journal, 4(1), 32-45.

[2] Hassan, M., \& Jagirani, T. S. (2019). Employee turnover in public sector banks of Pakistan. Market Forces, 4(1).

[3] Shahid, A., Saeed, H., \& Tirmizi, S. M. A. (2015). Economic development and banking sector growth in Pakistan. Journal of Sustainable Finance \& Investment, 5(3), 121-135

[4] Pinho, C. J., Rodrigues, P. A., \& Dibb, S. (2014). The role of corporate culture, market orientation and organizational commitment in organizational performance: the case of nonprofit organizations. Journal of Management Development, 33(4), 374-398

[5] Saeed, I., Waseem, M., Sikander, S., \& Rizwan, M. (2014). The relationship of turnover intention with job satisfaction, job performance, leader member exchange, emotional intelligence and organizational commitment. International Journal of Learning and Development, 4(2), 242-256.

[6] Robert, F. (2018). Impact of workplace bullying on job performance and job stress. Journal of Management Info, 5(3), 12-15.

[7] Chaudhry, N. I., Mahesar, H. A., \& Pathan, S. K. (2017). The mediating role of workplace interpersonal mistreatment: An empirical investigation of banking sector of Pakistan. IBT Journal of Business Studies (JBS), 1(1).
[8] Mohsan, F., Nawaz, M. M., Khan, M. S., Shaukat, Z., \& Aslam, N. (2011). Are employee motivation, commitment and job involvement inter-related: Evidence from banking sector of Pakistan. International Journal of Business and Social Science, 2(17).

[9] Saleem, Y., Kamran, M. R., Sabir, F., \& Iqbal, J. (2013). Career development an imperative of job satisfaction and career commitment: Empirical evidence from Pakistani employees in banking sector. Career Development, 5(21), 108-118.

[10] Duffy, M. (2009), "Preventing workplace mobbing and bullying with effective organizational consultation, policies and legislation", Consulting Psychology Journal: Practice and Research, Vol. 61 No. 3, pp. 242262.

[11] Cropanzano, R. and Mitchell, M.S. (2005), "Social exchange theory: an interdisciplinary review", Journal of Management, Vol. 31 No. 6, pp. 874-900.

[12] Reis, H.T., Collins, W.A. and Berscheid, E. (2000), "The relationship context of human behavior and development", Psychological Bulletin, Vol. 126 No. 6, pp. 844-872.

[13] Leymann, H. (1990b). Mobbing and psychological terror at workplaces", Violence and Victims, 5(2), 119-126.

[14] Brodsky, C.M., (1976). The Harassed Worker, Toronto, Lexington Books, DC Heath \& Company.

[15] Organ, D. W., \& Ryan, K. (1995). A metaanalytic review of attitudinal and dispositional predictors of organizational citizenship behavior. Personnel Psychology, 48(4), 775802.

[16] Katz, D. (1964). The motivational basis of organizational behavior. Behavioral Science, 9(2), 131-146.

[17] Smith, C., Organ, D. W., \& Near, J. P. (1983). Organizational citizenship behavior: Its nature and antecedents. Journal of Applied Psychology, 68(4), 653.

[18] Armstrong, M. (2006). A handbook of human resource management practice: Kogan Page Publishers.

[19] Deci, E. L., \& Ryan, R. M. (2010). Intrinsic motivation. The Corsini Encyclopedia of Psychology, 1-2. 
[20] Dermer, J. (1975). The interrelationship of intrinsic and extrinsic motivation. Academy of Management Journal, 18(1), 125-129.

[21] Rarbuto, J. E., \& Story, J. S. P. (2011). Work Motivation and Organizational Citizenship Behaviors. Journal of Leadership Studies, 5, 2334.

[22] Kemery, E. R., Bedeian, A. G., \& Zacur, S. R. (1996). Expectancy-Based Job Cognitions and Job Affect as Predictors of Organizational Citizenship Behaviors. Journal of Applied Social Psychology, 26(7), 635-651.

[23] Finkelstein, M. A. (2011). Intrinsic and extrinsic motivation and organizational citizenship behavior: A functional approach to organizational citizenship behavior. Journal of Psychological Issues in Organizational Culture, 2(1), 19-34.

[24] Ahmed, S., \& Khan, T. (2016). Does motivation lead to organizational citizenship behavior?-A Theoretical Review. Global Journal of Management and Business Research: A Administration and Management, 16(7), 43-49.

[25] Ibrahim, M. A., \& Aslinda, A. (2015). The effect of motivation on organizational citizenship behavior (OCB) at Telkom Indonesia in Makassar. Bisnis \& Birokrasi Journal, 21(2), 114-120.

[26] Volpe, M. and Reiter, N. (2013), "5 steps to head off workplace bullying", available at: http://restauranthospitality.com/eat-beatbusiness/5-steps-head-workplace-bullying (accessed 25 March 2018).
[27] Kitterlin, M., Tanke, M. and Stevens, D.P. (2016), "Workplace bullying in the foodservice industry", Journal of Foodservice Business Research, Vol. 19 No. 4, pp. 413-423.

[28] Sekaran, U., \& Bougie, R. (2016). Research methods for business: A skill building approach (Seventh ed.). Chichester, West Sussex, United Kingdom: John Wiley \& Sons.

[29] Hair, J. F., Black, W. C., Babin, B. J., Anderson, R. E., \& Tatham, R. L. (1998). Multivariate Data Analysis (Vol. 5): Prentice hall Upper Saddle River, NJ.

[30] Hayes, A. F. (2017). Introduction to mediation, moderation, and conditional process analysis: A regression-based approach: Guilford publications.

[31] Barbuto Jr, J. E., \& Scholl, R. W. (1998). Motivation sources inventory: Development and validation of new scales to measure an integrative taxonomy of motivation. Psychological Reports, 82(3), 1011-1022.

[32] Podsakoff, P. M., MacKenzie, S. B., Moorman, R. H., \& Fetter, R. (1990). Transformational leader behaviors and their effects on followers trust in leader, satisfaction, and organizational citizenship behaviors. The Leadership Quarterly, 1(2), 107-142.

[33] Kumar, M. M., \& Shah, S. A. (2015). Psychometric properties of Podsakoff's organizational citizenship behaviour scale in the Asian context. The International Journal of Indian Psychology, 3(1), 51-60. 